\title{
Paraplegia
}

\section{Work Status after Posterior Fixation of Unstable but Neurologically Intact Burst Fractures of Thoracolumbar Spine}

\author{
R. J. Huler, MD, ${ }^{1}$ S. I. Esses, MD, FRCSC, ${ }^{2}$ D. J. Botsford ${ }^{3}$ \\ ${ }^{l}$ Indiana University Medical Centre Indianapolis, USA, Toronto General Hospital, \\ University of Toronoto, Canada.
}

\begin{abstract}
Summary
Thirty nine patients with unstable burst injuries of the thoracolumbar junction who did not suffer neurological injury have been prospectively followed. There were 24 males and 15 females. Five patients were covered under the Workers' Compensation Board (WCB), The average patient age was 34 years (14-66). All patients were stabilised using the AO 'Fixateur Interne' and posterior fusion. The post-operative instrumented sagittal curve averaged six degrees of lordosis $(-20$ to +20$)$. The length of follow-up averaged 24 months (range 12-24). Pre-operatively 28 patients were employed, 2 were housewives, 6 were students, and 3 were unemployed. At follow-up, all students and housewives had returned to their usual activities. No patient who was initially unemployed had found work. Of the remaining 28 patients who were employed before injury, 23 (82\%) had returned to gainful employment, one had returned to school for job retraining, and 5 had not returned to work. Of the 23 patients who had returned to work, 5 returned to lighter duties, and 18 returned to their original occupation. Only 2 of the 5 WCB-covered patients did not return to work. Most neurologically intact patients undergoing surgery for unstable bursting injuries of the thoracolumbar spine can return to work.
\end{abstract}

The patient who has sustained a major injury to the spinal column faces many important decisions. He must grapple with the immediacy of financial hardship, possible vocational rehabilitation, and the threat of neurological injury. In addition, he may be counselled to undergo surgery for spinal stabilisation and reconstruction. Unfortunately, statistics portraying the long term functional results for urgent spinal trauma surgery are scarce. To prevent misunderstanding, the patient and surgeon must share similar expectations and treatment goals. The informed patient surgical consent must include possibilities for non-operative management and projected end results of operative management. In addition, third party insurance carriers, medicaid, medicare, and physician peer review organisa- 
tions now demand justification for expensive surgical procedures when nonsurgical options exist.

Clearly, follow-up data assessing post-rehabilitation vocational status is vitally important for the new patient. This information would also benefit social workers, government subsidising agencies, health care planners, and rehabilitation specialists. Our purpose was to accurately assess the long term functional work status after major posterior spinal reconstruction in accident surgery. This is defined as the postoperative ability to return to employment. A highly specialised subset of patients was selected to limit the number of variables which could influence the final outcome work status. Only patients undergoing posterior instrumentation and fusion were studied. Each patient presented with an unstable thoracolumbar spinal burst fracture with the potential for acute neurological deficit or late deformity. No patient in this series presented with neurological deficits at the time of accident. We wished simply to study the effects of major posterior spinal reconstruction in unstable thoracolumbar spine fractures on future employment status.

\section{Materials and methods}

Ninety five patients with unstable spine fractures treated by posterior instrumentation (AO Fixateur Interne) and fusion are being prospectively followed. Thirty nine patients were identified with unstable burst injuries of the thoracolumbar junction who did not suffer neurological injury at the time of injury, and they form the basis of this study. The remaining patients suffered either neurological compromise or spinal injuries other than burst fractures. There were 24 males and 15 females. Five patients were covered under the Workers' Compensation Board (WCB). The average patient age was 34 years (14-66). The average length of follow-up was 23 months (range 12-42 months). Data are reported once a patient has successfully returned to work, or in those patients where another suitable endpoint can be defined such as returning to school for job retraining. All patients continue to be prospectively followed under our spine fracture protocol.

Patient follow-up consisted of clinical examination and radiographic evaluation. Toronto General Hospital is a country-wide referral centre for spinal injuries. Patients often arrive by air ambulance over great distances for acute care of their spinal injuries. All patients for whom follow-up examination would cause inconvenience because of the large travel distance were personally interviewed and questioned by the authors over telephone. For these patients, referring physicians supplied follow-up radiographs and clinical examination follow-up data.

The system design of the AO spinal 'Fixateur Interne' has been well described. ${ }^{12,13,20}$ Basically it consists of Schanz screws, a coupling clamp, and fully threaded rods. The Schanz screws are $5.0 \mathrm{~mm}$ in diameter. The coupling device is freely mobile in the sagittal plane, allowing for angulation of the Schanz screws before securing them to the rod. The system allows axial, angular, and rotational adjustability. This permits the instrumented segments of the spine to be held in a variety of biomechanical modes, including distraction, compression, and derotation to restore anatomical spinal contours.

A standard posterior approach to the spine is used. The site of injury is exposed by sub-periosteal dissection. Schanz screws are inserted into the vertebral pedicles 
above and below the level of burst vertebrae. We rely on anatomical landmarks to identify a starting point for pedicle screw insertion, ${ }^{22}$ and subsequently verify correct placement with intra-operative radiographs once the screws have been inserted. Schanz screw entry into the most proximal instrumented pedicle was via the pars intra-articularis of the same superior instrumented vertebrae. This technique minimises potential damage to the most proximal facet joints not intended to be included within the fusion mass. With the screws inserted, the surgeon has powerful lever arms available to reduce the fracture. Distraction and restoration of appropriate sagittal spinal contours (lordosis) are necessary to decompress the spinal canal and correct deformity. ${ }^{21}$, ${ }^{25}$ All nuts are now tightened until stripped into place. Transverse traction devices (DTT) from the CotrelDubousset $^{6}$ spinal instrumentation were used to bridge the rods and provide increased rigidity through cross-linking. In each case autogenous posterior iliac crest bone graft supplemented a wide posterolateral fusion at each level immobilised by the implant.

All patients received prophylactic antibiotics immediately pre-operative and for 48 post operative hours. Prophylactic anticoagulation was begun on the first postoperative night and consisted of oral coumadin to keep the prothrombin time approximately one and one half times the normal hospital control. This was continued until the day of discharge. All patients were protected post-operatively with an external light weight thoracolumbar hyperextension orthosis for 4 months.

\section{Results}

The post-operative instrumented thoracolumbar sagittal curve averaged $6^{\circ}$ of lordosis (range $-20-+20^{\circ}$ ) measured using the Cobb Method. The length of follow-up averaged 24 months (range 12-42). Pre-operatively 28 patients were employed, 2 were housewives, 6 were students, and 3 were unemployed. At followup, all students and housewives had returned to their usual activities. No patient who initially was unemployed had found work. Of the remaining 28 patients who were employed before injury, $23(82 \%)$ had returned to gainful employment. This includes one patient who returned to lighter duties but has also returned to school for job retraining. Five patients have not returned to work. Of the 23 patients who had returned to work, 5 returned to different duties, and 18 returned to their original occupation. Only 2 of the 5 WCB-covered patients did not return to work.

\section{Discussion}

Previously, studies examining employment status following spinal column injury have focused on patients with residual neurological deficit. ${ }^{9}, 11,16-23,26$ In addition, authors who have described their treatment of thoracolumbar burst fractures most often concentrate on either instrumentation technique or radiographic alignment and bone healing. ${ }^{10,14,28-31,35,38}$ In these papers, little mention is made as to final occupational status. This would represent valuable information since the available data on spinal surgery, especially fusions for non-traumatic conditions, suggests that many patients do not return to the work force.

It is of interest to review the data of Denis et al and Weinstein. Denis et $\mathrm{al}^{8}$ 
compared operative and non-operative treatment of acute thoracolumbar burst fractures. In their review, of 13 patients who were neurologically intact (Frankel E) ${ }^{24}$ and treated with Harrington rods, only $46 \%$ returned to their former occupation. Indeed, of the 29 neurologically intact (Frankel E) patients treated nonoperatively, $65 \%$ returned to their former occupation or heavy labour. Weinstein ${ }^{39}$ presented a long-term follow-up of conservatively managed burst fractures.

Furthermore, there is evidence ${ }^{4,27,36}$ that the longer a patient is off work due to a back-related disorder, the worse is the prognosis for their return to work. In addition to the trauma of spinal column injury and possible surgical reconstruction, other factors weigh heavily in the determination of post-rehabilitation work status. Workers compensation benefits and pending litigation act as powerful financial disincentives for returning to work.

In this study, we followed a group of patients undergoing thoracolumbar fusion following trauma. Only 5 patients suffered trauma resulting in a compensable injury. All patients were neurologically intact immediately following injurh, and no patient lost neurological function post-operatively or at long term follow-up.

Pre-operatively, 28 patients were employed, 2 were housewives, 6 were students, and 3 were unemployed. At follow-up, all students and housewives had returned to activity (one housewife stated the need to decrease her level of physical activity from her usual pre-injury level). No patient who was initially unemployed had found work at follow-up. Of the 28 patients receiving employment pay checks before injury, 23 (82\%) returned to gainful employment, one returned to school for job retraining, and 5 were unable to work. Of the 23 patients who did return to work, 18 returned to their original occupation and 5 returned to a different, usually less physically strenuous occupation. Two of the 5 workers compensation board patients did not return to work. The number of patients receiving compensation benefits is too small to draw any conclusions regarding the effects of compensable injury on future work status.

We postulate three reasons for the favourable return to employment response after operative treatment for thoracolumbar burst fractures. First, the young age of our patients averaged 34 years at time of injury and most did not suffer from any pre-existing chronic conditions. Second, surgery was performed immediately following the injury, allowing for a short convalescent period. Third, the use of the AO 'Fixateur Interne' allows for stabilisation of burst fractures by fusing only two spinal motion units. ${ }^{12,13,20}$ This avoids many of the late complications seen with longer fusions, particularly in the lower lumbar spine. ${ }^{5}$ Trauma to the thoracolumbar spine as described by Denis ${ }^{7}$ may disrupt all three columns rendering an unstable spine which invites further damage and prohibits optimal nursing care. Unfortunately, spinal stabilisation using implants which rely on posterior element purchase such as the Harrington or Cotrel-Dubousset hook or Luque sub-laminar wire require immobilisation of at least five vertebral motion segments. ${ }^{10}, 14,28,30$, 31, 35, 38 These implants provide stability through distraction forces applied to the intact ligaments of uninjured, normal motion segments adjacent to the injured spinal motion segments. Therefore, uninjured vertebrae must be fused as well. It is well documented that multi-level fusions extending caudal to the third lumbar vertebrae may result in back pain and degeneration of the distal remaining vertebral motion segments. ${ }^{5}$ Implant systems providing stability for three-column injuries by immobilising fewer vertebrae are of great value. Transpedicular screws 
rigidly linked to plates or rods can provide three-column spinal stability through a posterior surgical approach. ${ }^{1-3,12,13,20,37}$ Stability is afforded by the implant itself. Fewer levels need to be immobilised compared with all other posterior element fixation systems such as the Harrington and Luque implants. Immobilisation of uninjured segments merely to provide stability through ligamentotaxis is not required. Non-operative treatment for these injuries requires long periods of external immobilisation using casts or orthoses followed by a period of intense rehabilitation. ${ }^{24,30,39}$ Other forms of surgical intervention include instrumenting long and fusing short. ${ }^{28}$ This approach requires restriction of some activities until the implant has been removed. This is undertaken some 9-12 months after the initial surgery. It is known to accelerate facet joint arthrosis in the canine model ${ }^{33}$ and human cartilage $\mathrm{e}^{32}$ as well. Anterior decompression, fusion, and stabilisation as described by Kostuik ${ }^{34}$ has the advantage of direct decompression of the neural canal in cases of progressive neurological deficit following burst fractures of the thoracolumbar spine. In addition Kostuik has reported an average of 1.6 Frankel grades in neurological improvement in patients with incomplete neurologic deficit. Satisfactory stabilisation of the thoracolumbar spine can be achieved through use of a single anterior approach with appropriate anterior stabilising implants. ${ }^{15}, 34$ Similar to posterior placed transpedicular implants, only a limited number of vertebrae need be included within the fusion mass. However, a transthoracic retroperitoneal surgical decompression and stabilisation in the immediate injury period is a formidable undertaking. Anterior approaches also require the use of strut grafts which require a long time to incorporate. During this period, patients are restricted in their activities. Our current protocol utilises the posteriorly placed AO 'Fixateur Interne' in ail cases of neurologically intact bursting fractures of the thoracolumbar spine. We reserve urgent anterior decompression and stabilisation for the patient presenting with incomplete but progressive neurologic deficit and demonstrated bony compression of the thecal sac by computed tomographic scans.

Our management of these injuries offers many advantages. Surgery is carried out as soon after the injury as the patient is deemed stable for an anaesthetic. The operative approach is posterior thus obviating recovery from a possible thoracotomy. Using the 'Fixateur Interne' only two spinal motion units are fused. The patients are encouraged to return to most activities at 3 months following surgery and have no restrictions at 6 months. No additional period of rehabilitation is required.

The 'Fixateur Interne' offers many advantages in the surgical management of thoracolumbar burst fractures. In this study, we have shown that the majority of patients can return to the work force. Most neurologically intact patients undergoing surgery for unstable bursting injuries of the thoracoloumbar spine can return to work. This is important for patient counselling and guidance. This information is of value to government agencies, social workers, insurance companies, and health care planners.

\section{References}

1. Abei M, Etter C, Kehl T, Thalgott J. 1987 Stabilization of the lower thoracic and lumbar spine with the internal spinal skeletal fixation system: Indications, techniques, and first results of treatment. Spine 12:544-551. 
2. Abei M, Etter C, Kehl T, Thalgott J. 1977 The internal skeletal fixation system: A new treatment of thoracolumbar fractures and other spinal disorders. Clin Orthop 117:30-43.

3. Abei M, Mohler J, ZaCH G, MorSChER E. 1986 Analysis of 75 operated thoracolumbar fractures and fracture disolocations with and without neurologic deficit. Arch Orthop Trauma Surg 105: $100-112$.

4. Better SR, Find PR, Simison D, Doss GH, Walls RT, McLaughlin DE. 1979 Disability benefits as disincentives to rehabilitation. Health and Society 57:412-427.

5. Cochran T, IrSTRAm L, NAChemson A. 1983 Long term anatomic and functional changes in patients with adolescent idiopathic scoliosis treated by Harrington rod fusion. Spine 8:576-589.

6. Cotrel Y, Dubousset J. 1984 Nouvelle technique d'osteosynthese rachidienne seqmentaire par voie posterieur. Rev chir Orthop 70:489.

7. DENIS F. 1983 The three column spine and its significance in the classification of acute thoracolumbar spinal injuries. Spine 8:817.

8. Denis F, Armstrong GWD, Searls K, Matta L. 1984 Acute thoraculumbar burst fractures in the absence of neurologic deficit: A comparison between operative and nonoperative treatment. Clin Orthop 189:142-149.

9. DeVIVo MJ, FINE PR. 1982 Employment status of spinal cord injured patients 3 years after injury. Arch Phys Med Rehabil 63:200-203.

10. DEWALD RL. 1984 Burst fractures of the thoracic and lumbar spine. Clin Orthop 189:150-161.

11. Deyoe FS JR. 1972 Spinal Cord Injury: Long-term follow-up of veterans. Arch Phys Med Rehabil 53:523-529.

12. Dick W. 1987 The 'Fixateur Interne' as a versatile implant for spine surgery. Spine 12:882-900.

13. Dick W, Kluger P, Magerl F, Worsdorfer O, Zach G. 1985 A new device for internal fixtation of thoracolumbar and lumbar spine fractures: The 'Fixateur Interne.' Paraplegia 23:225-232.

14. DiCKSON JH, HARRINGTON PR, IRWIN WD. 1978 Results of reduction and stabilization of the severely fractured thoracic and lumbar spine. J Bone Joint Surg 60A:799.

15. DunN HK. 1984 Anterior stabilization of thoracolumbar injuries. Clin Orthop 189:116-124.

16. Dvonch P, Kaplin LI, Grynbaum BB, Rush HA. 1965 Vocational findings in postdiability employment of patients with spinal cord dysfunction. Arch Phys Med Rehabil 46:761-766.

17. El Ghatit AZ, Hanson RW. 1979 Educational and training levels and employment of spinal cord injured patient. Arch Phys Med Rehabil 60:405-406.

18. El Ghatit AZ, HaNSON RW. 1978 Variables associated with obtaining and sustaining employment among spinal cord injured males: Follow-up of 760 veterans. J Chronic Dis 31:363-369.

19. ERICKSON DL, LEIDER LL JR, BROWN WE. 1977 One-stage decompression-stabilization for thoracolumbar fractures. Spine 2:53.

20. EsSES SI. 1989 The AO spinal internal fixator. Spine 14:373-378.

21. EsSes SI, SEemann PS, MAGERL FP. 1986 Clearance of the spinal canal by distraction in thoracolumbar and lumbar fractures. Presented at the annual meeting of the Scoliosis Research Society, Hamilton, Bermuda, September 21-25.

22. ESSES SI, BEDNAR DA. 1989 The spinal pedicle screw: Techniques and systems. Orthopaedic Review 18:676-682.

23. Felton JS, Litman M. 1965 Study of employment of 222 men with spinal cord injury. Arch Phys Med Rehab 46:809-814.

24. Frankel HL, HANCOCK DO, Hyslop G et al. 1969 The value of postural reduction in initial management of closed injuries of the spine with paraplegia and tetraplegia. Paraplegia 7:179-192.

25. FREDRICKSON EB, MANN KA, YuAN HA, LubiCKY JP. 1988 Reduction of the intracanal fragment in experimental burst fractures. Spine 13:286-293.

26. GEISLER WO, JouSSE AT, WYNNE-JoNES M. 1966 Vocational re-establishment of patients with spinal cord injury. Med Serv J Can 22:698-709.

27. GREENOUGH CC, FRASER RD. 1989 The effects of compensation on recovery from low-back injury. Spine 14:947-955.

28. HAzel WA JR et al. 1988 Vertebral fractures without neurologic deficit. A long-term follow-up study. J Bone Joint Surg 70A:1319-1321.

29. JACOBS RR, CASEY MP. 1984 Surgical management of thoracolumbar spinal injuries: General principles and controversial considerations. Clin Orthop 189:22-35.

30. JACOBS RR, ASHER MA, SNIDER RK. 1980 Thoracolumbar spinal injuries: A comparative study of recumbent and operative treatment in 100 patients. Spine 5:463.

31. Leshold WR, WeINSTEIN SL, SPRAGUE BL. 1981 Thoracolumbar spine fractures: Results of treatment. Spine 6:13-34.

32. Kahanovitz N, Bullough P, JaCoBs R. 1984 The effect of internal fixation without arthrodesis on human facet joint cartilage. Clin Orthop 189:204-208. 
33. Kahanovitz N, ARnOCZky SP, Levine DB, Otis JP. 1984 The effects of internal fixation on the articular cartilage of unfused canine facet joints. Spine 9:268.

34. KostuIK JP. 1981 Anterior fixation for fractures of the thoracic and lumbar spine with or without neurologic involvement. Clin Orthop 189:103-115.

35. McEvoY RD, BRADFORD DS. 1985 The management of burst fractures of the thoracic and lumbar spine: Experience in 53 patients. Spine 10:631-637.

36. NaChemson A. Work for all: For those with low back pain as well. Clin Orthop 179:77-85.

37. Olerud S, Karlstrom G, SJostrom L. 1988 Transpedicular fixation of thoracolumbar vertebral fractures. Clin Orthop 227:44-51.

38. Osebold WR, Weinstein SL, SPRAgUe BL. 1981 Thoracolumbar spine fractures: Results of treatment. Spine 6:13-34.

39. WEINSTEIN JN et al. 1988 Thoracolumbar 'burst' fractures treated conservatively: A long-term follow-up. Spine 13:33-38. 